$\underline{\text { SUPPORTING INFORMATION }}$

\title{
LOW-MOLECULAR-WEIGHT BRANCHED POLYETHYLENIMINE POTENTIATES AMPICILLIN AGAINST MRSA BIOFILMS
}

Anh K. Lam, Hannah Panlilio, Jennifer Pusavat, Cassandra L. Wouters, Erika L. Moen, Andrew J. Neel, and Charles V. Rice*

Department of Chemistry and Biochemistry, Stephenson Life Sciences Research Center, University of Oklahoma, 101 Stephenson Parkway, Norman, OK 73019

Dr. Charles V. Rice (*corresponding author)

Tel: 405-325-5831

Fax: 405-325-6111

Email: rice@,ou.edu

\section{EXPERIMENTAL PROCEDURE}

\section{Materials}

In this experiment, the Staphylococcus aureus (MRSA 43300) was purchased from the American Type Culture Collection. Two MRSA clinical isolates (MRSA OU6 \& OU11) from patient swabs were kindly provided by Dr. McCloskey from the University of Health Sciences Center with an institutional review board (IRB) approval. Chemicals (DMSO, growth media, and electron microscopy fixatives) were purchased from SigmaAldrich. Antibiotics (ampicillin and polymyxin B) were purchased from Gold Biotechnology. 600 Da BPEI was purchased from Polysciences. MBEC ${ }^{\text {TM }}$ Biofilm Inoculators were purchased from Innovotech. Isopore polycarbonate membrane filters $(0.1 \mu \mathrm{m}$ pore size, hydrophilic, $13 \mathrm{~mm}$ diameter $)$ were purchased from MilliporeSigma.

\section{MBEC Assay}

This method is adapted from our previous study. ${ }^{1}$ In brief, bacterial culture was inoculated in an MBEC pronged-inoculator and incubated for $24 \mathrm{hr}$ to allow biofilm formation. Then, the preformed biofilm prong lid was washed and treated in a separate challenge plate which was prepared as a checkerboard assay: ${ }^{2}$ serial dilutions of BPEI and antibiotic solutions were added to a 96-well base plate with a total volume of $200 \mu \mathrm{L}$ cation-adjusted Muller Hinton broth (MHB) per well. The change in optical density at $600 \mathrm{~nm}\left(\Delta \mathrm{OD}_{600}\right)$ was measured. Minimum inhibitory concentration (MIC) of each drug is determined as the lowest concentration that inhibited cell growth $\left(\triangle \mathrm{OD}_{600}<0.05\right)$. Fractional inhibitory concentration index $(\mathrm{FICI})$ was calculated as: $F I C I=\frac{M I C_{A B}}{M I C_{A}}+\frac{M I C_{B A}}{M I C_{B}}$. Synergistic effects are determined using EUCAST guidelines: synergy (FICI $\leq 0.5)$, additivity $(0.5<$ FICI $<1)$, and indifference $(\mathrm{FICI}>1) .{ }^{3}$ The treated pronged-inoculator was then washed and transferred to a recovery plate with $200 \mu \mathrm{L} \mathrm{MHB/well} \mathrm{to} \mathrm{sonicate} \mathrm{and} \mathrm{recover} \mathrm{any} \mathrm{remaining} \mathrm{biofilm} \mathrm{bacteria.} \mathrm{The} \mathrm{recovery} \mathrm{plate} \mathrm{was} \mathrm{then}$ incubated overnight before measuring $\triangle \mathrm{OD}_{600}$ to determine MBECs and FICIs of the drugs tested on the biofilms. 


\section{Biofilm Disrupting Assay}

This method is also described in details by Lam et al. ${ }^{1}$ This experiment was parallelly conducted with polymyxin B (PmB, a cationic polypeptide antibiotic) and BPEI. In short, an overnight MRSA OU 6 culture was inoculated in a tissue-culture treated 96 -well plate $(100 \mu \mathrm{L}$ of tryptic soy broth or TSB/well) with an inoculation size of $1 \mu \mathrm{L} /$ well $\left(\sim 5 \times 10^{5} \mathrm{CFU} / \mathrm{mL}\right)$. The plate was incubated at $35{ }^{\circ} \mathrm{C}$ for $24 \mathrm{hr}$ to allow the bacteria to form biofilm. It was then washed with water to remove planktonic bacteria and stained with $100 \mu \mathrm{L}$ of crystal violet solution $(0.1 \%)$ per well for $15 \mathrm{~min}$. The stained plate was washed excessively with water 5 times to remove any unbound stain and air-dried overnight. Vary concentrations of PmB $(64$ and $128 \mu \mathrm{g} / \mathrm{mL})$ and 600 Da BPEI (64 and $128 \mu \mathrm{g} / \mathrm{mL}$ ) were added to the stained-biofilm plate with a total volume of $100 \mu \mathrm{L} / \mathrm{well}$. A negative control (water only) and positive control (30\% acetic acid) were also conducted at the same time of treatment. After 20 $\mathrm{hr}$, without touching the biofilm layer in the bottom of the plate, solubilized solution in each treated well was carefully transferred to a new 96 -well plate for an $\mathrm{OD}_{550}$ measurement, which represents the corresponding amount of biofilm disrupted by each treatment.

\section{Scanning Electron Microscopy (SEM)}

MRSA OU6 were inoculated from $0.5 \%$ of an overnight culture on glass coverslips and grown at $35{ }^{\circ} \mathrm{C}$. After $24 \mathrm{hr}$. the biofilm-formed on glass coverslips were carefully removed and washed in water for $10 \mathrm{~s}$. Then each sample was submerged in different treated solution (untreated control, $128 \mu \mathrm{g} / \mathrm{mL}$ BPEI-treated, and bleachpositive control) for another $24 \mathrm{hr}$. Next, they were removed, washed in water for $10 \mathrm{~s}$, and submerged in primary fixative ( $5 \%$ glutaraldehyde in $0.1 \mathrm{M}$ cacodylate buffer) and incubated at $4 \pm 2{ }^{\circ} \mathrm{C}$ for 2 days. The glass coverslips were removed from the fixing solution and air-dried for $72 \mathrm{hr}$. They were mounted on aluminum stubs with carbon tape and sputter-coated with AuPd. A Zeiss NEON SEM was used to image the samples at $5 \mathrm{kV}$ accelerating voltage.

\section{SEM of Biofilms on Polycarbonate Membrane Filters}

Pre-sterilized polycarbonate (PC) membranes were gently adhered to a tryptic soy agar plate using sterilized forceps. A volume of $2 \mu \mathrm{L}$ of the stock MRSA OU6 solution $\left(\sim 5 \times 10^{5} \mathrm{CFU} / \mathrm{mL}\right)$ was pipetted on top of each PC membrane and incubated at $35^{\circ} \mathrm{C}$ for $7-8 \mathrm{hr}$, when the MRSA biofilm colony on the PC membranes became visible to the naked eye. The PC membranes with preformed biofilm was then carefully removed off the agar, transferred into a treatment solution of $256 \mu \mathrm{g} / \mathrm{mL}$ BPEI, and incubated for another $20 \mathrm{hr}$. Untreated and treated PC samples were removed and washed in water for $10 \mathrm{~s}$. They were submerged in primary fixative $(5 \%$ glutaraldehyde in $0.1 \mathrm{M}$ cacodylate buffer) and incubated at $4 \pm 2{ }^{\circ} \mathrm{C}$ for 2 days. The PC samples were air-dried slowly for 3 more days. They were mounted on aluminum stubs with double-side carbon tape, sputter-coated with $\mathrm{AuPd}$, and imaged at $5 \mathrm{kV}$ accelerating voltage by a Zeiss Neon SEM. 


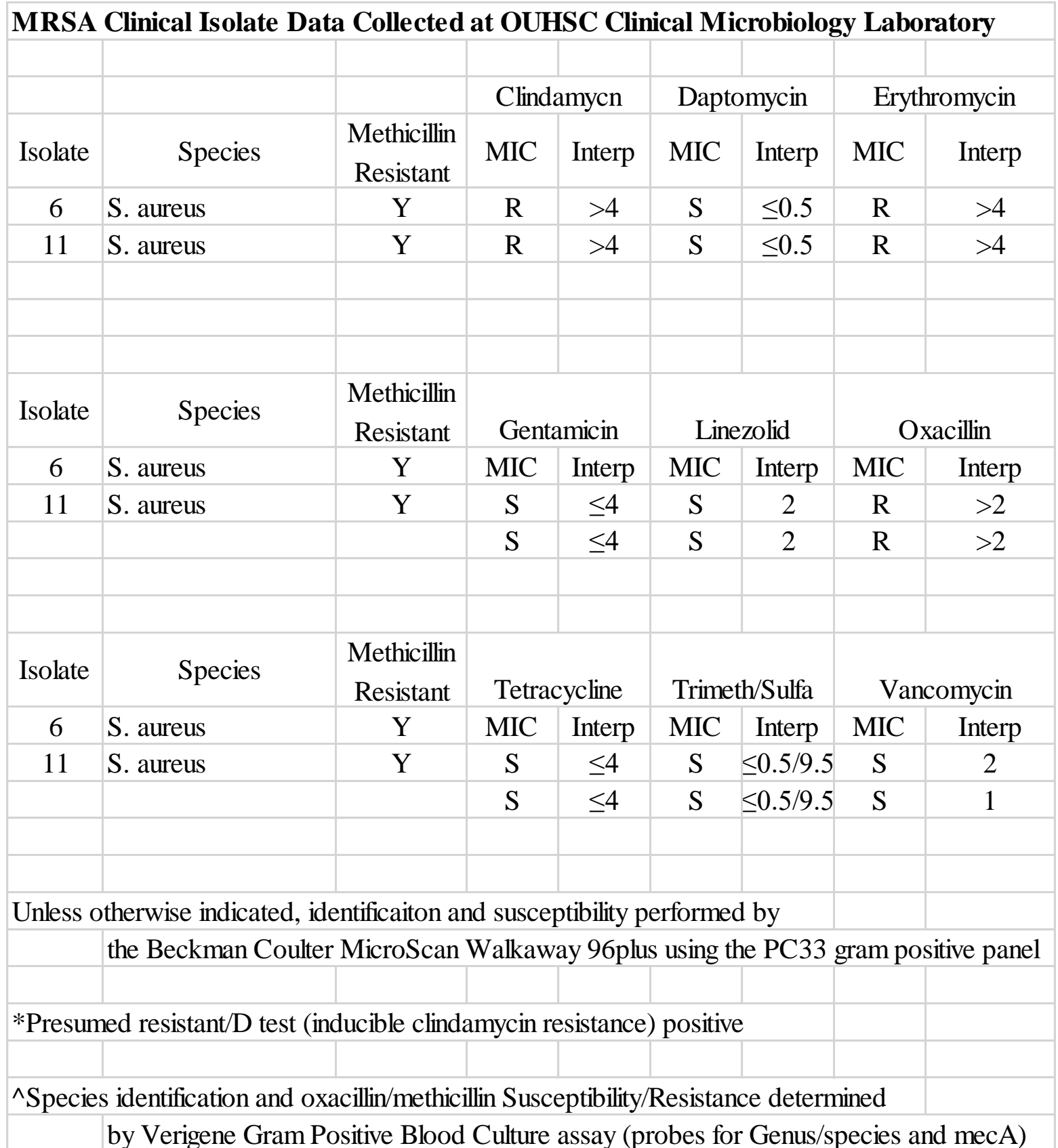

\section{$\underline{\text { Citations }}$}

1. Lam, A. K.; Wouters, C. L.; Moen, E. L.; Pusavat, J.; Rice, C. V., Antibiofilm Synergy of beta-Lactams and Branched Polyethylenimine against Methicillin-Resistant Staphylococcus epidermidis. Biomacromolecules 2019, 20 (10), 3778-3785.

2. $\quad$ Lam, A. K.; Hill, M. A.; Moen, E. L.; Pusavat, J.; Wouters, C. L.; Rice, C. V., Cationic Branched Polyethylenimine (BPEI) Disables Antibiotic Resistance in Methicillin-Resistant Staphylococcus epidermidis (MRSE). ChemMedChem 2018, 13 (20), 2240-2248.

3. $\quad$ European Committee for Antimicrobial Susceptibility Testing of the European Society of Clinical, M.; Infectious, D., EUCAST Definitive Document E.Def 1.2, May 2000: Terminology relating to methods for the determination of susceptibility of bacteria to antimicrobial agents. Clin Microbiol Infect 2000, 6 (9), 503-8. 